\title{
ALGUNAS REFLEXIONES POLÍTICAS SOBRE LA NATURALEZA DEL MATRIMONIO Y LA FAMILIA Miguel Ayuso
}

\section{Introducción}

Si admitimos que la doctrina social de la Iglesia, en sentido estricto, esto es, en su significación moderna, no es sino la «contestación cristiana del mundo moderno», se comprende que el propio magisterio eclesiástico en la edad contemporánea haya tenido el carácter diferencial de ocuparse, de un modo inusitado en siglos anteriores, de cuestiones de orden político, cultural, económico-social etc., ofreciéndonos todo un cuerpo de doctrina centrado en la proclamación del Reinado de Cristo sobre las sociedades humanas como condición única de su ordenación justa y de su vida progresiva y pacífica (1). Es cierto también, sin embargo, que el modernismo, combatido en los primeros decenios del siglo XX y en rigor nunca vencido, campante en los años del II Concilio Vaticano y en los posteriores, extendió una ola de conformismo con el mundo que iba a poner en la penumbra la realeza social de Jesucristo como centro de aquella predicación. Que llega hasta nuestros días (2). El

(1) Francisco Canals, «La doctrina social de la Iglesia», Verbo (Madrid), núm. 255-256 (1987), págs. 639 y sigs.

(2) Cfr. Miguel Ayuso, La constitución cristiana de los Estados, Barcelona, Scire, 2008, págs. 28 y sigs. Para una evaluación crítica del problema, véase Bernard Dumont, Miguel Ayuso y Danilo Castellano (eds.), Iglesia y política. Cambiar de paradigma, Madrid, Itinerarios, 2013. Ese conformismo de base no ha excluido en ocasiones reacciones radicales contra el «orden» imperante, taradas en el fondo por la progenie de sus premisas. En este sentido, si la doctrina social de la Iglesia es la «contestación» cristiana del mundo moderno, se han alzado frente a éste otras «contestaciones», como la marxista, dependientes en todo caso del universo contra el que reaccionaban, que han inficionado a veces la «cultura católica». Cfr. la explicación de Jean Madiran, L'hérésie du XX siècle, París, NEL, 1968: «En 
MIGUEL AYUSO

corazón de la resistencia se desplazó, pues, abandonada la comunidad política, a la familia y a la persona, sobre las que se concentran las agresiones de la modernidad.

En León XIII encontramos una exposición canónica del papel e importancia de la familia: «He aquí, pues, la familia o sociedad doméstica, bien pequeña, es cierto, pero verdadera sociedad y más antigua que cualquiera otra, la cual es de absoluta necesidad que tenga unos derechos y unos deberes propios, totalmente independientes de la potestad civil. Por tanto, es necesario que ese derecho de dominio atribuido por la naturaleza a cada persona, según hemos demostrado, sea transferido al hombre en cuanto cabeza de la familia; más aún, ese derecho es tanto más firme cuanto la persona abarca más en la sociedad doméstica [...]. Al igual que el Estado, según hemos dicho, la familia es una verdadera sociedad, que se rige por una potestad propia, esto es, la paterna. Por lo cual, guardados efectivamente los límites que su causa próxima ha determinado, tiene ciertamente la familia derechos por lo menos iguales que la sociedad civil para elegir y aplicar los medios necesarios en orden a su incolumidad y justa libertad. Y hemos dicho "por lo

el mundo moderno, la contestación cristiana y la marxista tienen más o menos la misma edad. El Syllabus es el resumen de encíclicas y alocuciones de Pío IX, que son contemporáneas a las obras de Marx. Y los comunistas, en sus seminarios, estudian esta historia que vosotros [se dirige a los obispos] ocultáis a los seminaristas cristianos y a los estudiantes católicos. Pío IX se convirtió en Papa dos años antes del Manifiesto, promulgó el Syllabus tres años antes de la aparición del Capital. Las dos contestaciones han comenzado a formularse explícitamente más o menos en los mismos años. $\mathrm{Y}$ han seguido luego paralela su marcha, de un lado las encíclicas sociales, del otro los escritos y la acción de Lenin. Los militantes comunistas son instruidos cuidadosamente en su historia, se les enseña a ser orgullosos de ella. Los militantes cristianos son privados de la suya: se les enseña a despreciarla globalmente y a creer que el futuro empieza hoy. La contestación marxista es una falsificación diabólica de la contestación cristiana. Por contenido y finalidad son rigurosamente opuestas. La contestación cristiana se eleva contra las injusticias y los contrasentidos del mundo moderno y busca restablecer el orden natural. La contestación marxista usa como pretexto estos contrasentidos e injusticias pero para alzarse contra el orden natural y destruir lo que de él queda aún. Por lo que estas injusticias y contrasentidos serán finalmente conducidos a un punto horrible de perfección por el comunismo» (pág. 300). 
menos" iguales, porque, siendo la familia lógica y realmente anterior a la sociedad civil, se sigue que sus derechos y deberes son también anteriores y más naturales. Pues si los ciudadanos, si las familias, hechos partícipes de la convivencia y sociedad humanas, encontraran en los poderes públicos perjuicio en vez de ayuda, un cercenamiento de sus derechos más bien que una tutela de los mismos, la sociedad sería, más que deseable, digna de repulsa» (3).

Y en Pío XII están ya presentes los calificativos más frecuentes en nuestros días: la familia, «como fuente y escuela de la vida», junto con el Estado, «como tutor del derecho», «son las dos columnas principales, la armadura de la sociedad humana» (4); la familia es la «célula insustituible del pueblo» (5).

Igualmente hallamos una tal insistencia en Juan Pablo II: «La familia es la célula primaria de la sociedad. Esta apoyada en la sólida base del derecho natural, que une a todos los hombres y todas las culturas. Urge tomar conciencia de este aspecto, que me propongo seguir tratando los próximos domingos. En efecto, con frecuencia se interpreta equivocadamente la insistencia de la Iglesia en la ética del matrimonio y de la familia, como si la comunidad cristiana quisiera imponer a toda la sociedad una perspectiva de fe válida sólo para los creyentes. Esto se ha visto, por ejemplo, en algunas reacciones al desacuerdo que manifesté abiertamente, cuando el Parlamento europeo pretendió legitimar un nuevo tipo de familia, caracterizada por la unión de personas homosexuales. En realidad, el matrimonio, como unión estable de un hombre y de una mujer que se comprometen a entregarse recíprocamente y se abren a la generación de la vida, no es sólo un valor cristiano, sino también un valor originario de la creación. Perder esta ver-

(3) Rerum novarum, §9. Más adelante dejamos alguna precisión sobre una parte del contenido de este texto.

(4) «La Iglesia en la verdadera restauración del mundo. Alocución de 20 de febrero de 1946 a los nuevos cardenales», Colección de encíclicas y documentos pontificios, Madrid, ACE, 1967, tomo I, pág. 225. Pío XII subraya el origen paulino de esa doble estructura: los fieles son «conciudadanos de los santos y miembros de la familia de Dios» (Ef. 2,19).

(5) «El orden interior de las naciones. Radiomensaje de Navidad de 1942», Colección de encíclicas y documentos pontificios, cit., tomo I, pág. 356. 
MIGUEL AYUSO

dad no sólo es un problema para los creyentes, sino también un peligro para toda la humanidad» (6).

No hace al caso multiplicar las citas. La insistencia del magisterio de la Iglesia y del pensamiento católico en torno a la importancia de la familia y sus derechos en la sociedad se compadecería con el eclipse de la familia en la disociedad contemporánea $(7)$.

\section{El «eclipse» de la familia}

De la familia se han dado muchas definiciones, coherentes con los distintos aspectos de la misma: la sociedad conyugal, la parental o la doméstica. Pero, en el pasado, esas aproximaciones, centrándose en un aspecto de la realidad familiar, no excluían a las demás. A diferencia de lo que ocurre en nuestros días, donde las definiciones (consiguientes a la aproximaciones) diversas esconden con frecuencia errores conceptuales (8).

Dice Aristóteles que la familia es una comunidad que se constituye para la vida cotidiana según la naturaleza (9). Se trata de una definición, que ofrece un concepto, extraído de la observación de lo «dado», esto es, de la realidad (10).

La familia -en primer lugar- se constituye, lo que remite a su comienzo: el matrimonio. Contrato que requiere el libre consentimiento de las partes y tiene por causa la procreación y educación de los hijos (que el mismo Aristóteles

(6) «Meditación mariana el domingo 19 de junio», L'Osservatore Romano, edición semanal en lengua española, año XXVI, núm. 25 (1.330), 24 de junio de 1994.

(7) Marcel DE CORTE, «De la sociedad a la termitera pasando por la disociedad», Verbo (Madrid), núm. 131-132 (1975), págs. 93 y sigs.

(8) Lo ha observado el profesor Danilo CASTELLANO, "Tramonto o eclisse della famigilia?», en este mismo volumen.

(9) Aristóteles, Política, I 1252a.

(10) Cfr. la ilustración de la definición aristotélica que hace Danilo CASTELlAnO, «Della famigilia: brevi consideración sulla sua essenza, sulle sue finalità e sulla principale causa della sua attuale decadenza», en Miguel Ayuso (ed.), Dalla geometria legale-statualistica alla riscoperta del diritto e della politica. Studi in onore di Francesco Gentile, Madrid, Marcial Pons, 2006, págs. 207 y sigs. 
denomina «impulso natural»). El primero supone la premisa de la donación total y recíproca de los cónyuges, necesaria para que sus «criaturas» alcancen lo que por naturaleza son.

En segundo lugar, si la familia se constituye es para una necesidad exigida por el orden natural. Es necesario, sigue Aristóteles, que se unan los seres que no pueden existir separados el uno del otro. Así, la existencia del varón y de la mujer está en función de la procreación. Lo que no es convencional ni dependiente de opciones individuales, sino dispuesto por la naturaleza que nos muestra cómo nada se hace sin finalidad. Y lo que, de resultas excluye, una familia (matrimonio) homosexual, pues la voluntad no puede imponerse sobre la realidad, así como el pensamiento no es sinónimo de la fantasía (11).

A continuación, la familia se constituye para la vida cotidiana, esto es, para atender necesidades naturales y exigencias humanas de la vida de cada día. Que esas necesidades son «naturales» y esas exigencias «humanas» significa que ni son inducidas, ni meras pasiones ni opciones irracionales. En resumen, la familia sirve para evitar el desorden: «Debiendo educar a los hijos, presupone que los educadores (los que "mandan" diría Aristóteles) eduquen según la racionalidad, esto es, según el orden de la naturaleza que impone a todos alcanzar y usar la racionalidad (característi-

(11) El magistrado brasileño Ricardo M. DIP, «A familia e os novos modelos de união sexual», en este mismo volumen, lo ha explicado con acierto: «En su concepción tradicional, la familia es una comunidad que corresponde a la naturaleza del hombre. Esa idea de familia, y su realidad, está siendo atacado en los últimos tiempos por movimientos ideológicos que, extendiendo a las varias especies de unión sexual el nombre de "familia", tratan de obtener un régimen jurídico similar al de la comunidad familiar tradicional. Sin embargo, mientras que la familia tiene por fin principal la generación y educación de los hijos, los "nuevos" modelos de unión sexual apenas miran a la satisfacción de las pulsiones, negando la identidad biológica de los hombres y rechazando los fines sociales de la familia como institución natural. Esos "nuevos" modelos son reminiscencias de propuestas ya deshilachadas, de modo infecundo, en los siglos XVIII y XIX, y configuran la consagración del individualismo, al ser su lógica interna susceptible de amparar la institucionalización de cualquier modo de unión sexual». 
ca propia del ser humano) para poder vivir autónomamente, es decir, individuando por sí mismos las normas que la naturaleza humana impone respetar al hombre para serlo. Presupone también, sin embargo, un orden que no es impuesto por la voluntad arbitraria de otros (y, por lo mismo, meramente convencional), sino que forma parte de nosotros mismos, más aún, que es nuestro ser esencial. El legislador, por tanto, no puede legítimamente aprobar cualquier legislación relativa al derecho de familia, por estar él mismo vinculado al orden de la misma familia» (12).

Finalmente, la familia es una comunidad y no una mera sociedad (13). Requiere, como ésta, un principio formal que la haga «una», pero reclama una adhesión que no es simplemente voluntaria o jurídica. La comunidad es esencialmente voluntad orgánica en torno a un sobre-tí, animada por un espíritu interno. Reconoce orígenes religiosos y naturales y no simplemente convencionales o pactados. Posee lazos internos, no sólo voluntarios y racionales, sino

(12) Danilo Castellano, «Tramonto o eclisse della famigilia?», loc. cit.

(13) Algunos autores han realizado laudables pero erróneos esfuerzos en favor del reconocimiento civil de un (opcional) matrimonio indisoluble, como religiosamente lo es el celebrado entre católicos. Nuestra disconformidad con el actual régimen jurídico positivo del matrimonio en España, parte de que en el mismo no se reconoce el matrimonio religioso, como tal y con todo su contenido. Hoy no existe en España, según el derecho positivo, más que el matrimonio civil y disoluble, aunque éste pueda celebrarse con forma religiosa. Ahí está el punto de partida de la legalidad positiva vigente, con la cual nos hallamos en radical desacuerdo; pues entendemos: primero, que el verdadero matrimonio es esencialmente indisoluble; y, segundo, que el matrimonio religioso debe ser reconocido tal como canónicamente es regulado y no sólo en cuanto su forma sino en toda su regulación, efectos y jurisdicción competente. Lo explica claramente, en este mismo volumen, el profesor José María SÁNCHEZ, «El matrimonio, institución de derecho natural, ante el derecho del Estado»: «No es conforme con la consideración del matrimonio como institución de Derecho natural que sean los contrayentes, quienes en uso de la autonomía de la voluntad, configuren el estatuto jurídico de tal institución. Por lo demás, es dudoso que esta sea la actitud social y política más eficiente en la necesaria reconstrucción del matrimonio». Es de advertir una contaminación del llamado "comunitarismo», en puridad un liberalismo de radio colectivo en el seno del mundo «americanista». Cfr. Miguel Ayuso, El Estado en su laberinto. Las transformaciones de la política contemporánea, Barcelona, Scire, 2011, caps. 3 y 4 especialmente. 
emocionales y de actitud. Ejemplos típicos son la familia, la patria, la iglesia. En una comunidad, el carácter constitutivo que el deber tiene siempre respecto al derecho ha de hallarse en «la incisión en ella de un orden sobrenatural que posee el primario derecho a ser respetado, esto es, la aceptación comunitaria de unos derechos de Dios que determinan deberes radicales en el hombre y en la sociedad». La sociedad, en cambio, es voluntad reflexiva, convención. Las partes son en ella antes que el todo, y la voluntad es consecutiva a un pensamiento. Es la forma sociológica que está en la base de las sociedades voluntarias: mercantiles, de recreo, etc. Pero cuando se extiende a la convivencia humana radical -que siempre ha de ser una comunidad y que requiere, por usar términos de raigambre agustiniana, una anterior concordia- se produce la ruina. Porque en la sociedad, «el deber sigue siempre a un derecho personal y se define por razón del respeto debido a ese previo derecho» (14). El corolario jurídico, por ir cerrando el círculo abierto al comienzo de estas páginas, es, pues, palmario. Pues la comunidad precisa de un orden jurídico como orden del servicio personal exigible, mientras que las formas societarias se limitan a pretender articular vanamente un «ordenamiento jurídico»-que no guarda relación con el «orden»- simple constelación de derechos subjetivos o potestades individuales $(15)$.

Hoy, consiguientemente, nos hallamos ante un verdadero «eclipse de la familia». El igualitarismo y el democratismo contemporáneos sufren con dificultad los restos de desigualdad natural de los que la familia constituye una reserva privilegiada.

(14) La distinción fue formulada por Ferdinand Tönnies en Gemeinschaft und gesselschaft (1887). Cfr. Rafael GAMBRA, «La idea de comunidad en Joseph de Maistre», Revista Internacional de Sociología (Madrid), núm. 49 (1955), págs. 57 y sigs.; La unidad religiosa y el derrotismo católico, Sevilla, ECESA, 1965; «Comunidad y coexistencia», Verbo (Madrid), núm. 101 (1972), págs. 51 y sigs.

(15) Cfr. Álvaro D’́ORs, Nueva introducción al estudio del derecho, Madrid, 1999, págs. 71 y sigs. Francesco Gentile, El ordenamiento jurídico entre la virtualidad y la realidad, Madrid, Marcial Pons, 2001, presenta magistralmente las aporías de la «geometría legal» positivista. 
MIGUEL AYUSO

En efecto, si empezamos por el primero, la naturalidad de la desigualdad humana se presenta de manera especial en la estructura familiar: «Se funda ésta ya en la necesaria desigualdad natural del sexo de los cónyuges. A ella hay que añadir la desigualdad también natural entre padres e hijos, entre parientes más o menos próximos, por sangre, por adopción de hijos ajenos, o por afinidad con los parientes del cónyuge. La misma parentela que forma una "gran familia" se compone de desiguales [...]. Asimismo, existen dentro de las familias otras desigualdades que pueden acentuar las diferencias entre sus miembros, como el celibato, la viudez, la ancianidad, la profesión o el patrimonio» (16).

Si pasamos al segundo, también la familia resulta particularmente resistente a la democracia. En una visión profunda de las llamadas formas de gobierno hallamos que se corresponden con el papel político que asignan a la familia. La monarquía es así la forma en la que la familia conserva su peso político y en la que el gobierno se atribuye a una familia (la familia real) que corona un entramado de familias. En las oligocracias, sin embargo, se da una conmixtión

(16) Álvaro D’Ors, Nueva introducción al estudio del derecho, cit., págs. 94-95. El autor va más allá, al punto de escribir -en otro lugar de la misma obra- que «siendo la familia un concierto de desiguales, requiere un criterio de discriminación que perfile sus límites». Discriminación esencial que está, ante todo, en «la legitimidad del matrimonio y de la filiación que de él deriva»: «Sin la discriminación de lo ilegítimo, la familia no puede subsistir. No se trata de no reconocer los deberes que los progenitores tienen respecto a su prole, especialmente el deber de manutención cuando la prole no se vale por sí misma, sino de no confundir las uniones conyugales y las proles, pues esta indiscriminación conduce a la promiscuidad. En efecto, si la descendencia ilegítima tiene que poder convivir con la legítima, no se puede negar el mismo reconocimiento a las posibles, incluso múltiples, uniones conyugales. También el derecho de sucesión queda profundamente perturbado por la inseguridad de las expectativas de los ilegítimos. Así, cuando el derecho de sucesión da ciertas ventajas a los descendientes de un anterior matrimonio legítimo, la equiparación de hijos legítimos e ilegítimos viene a hacer imposible la observancia de tal derecho sucesorio». Por lo que, «el principio de legitimidad, como más natural que la legalidad, radica precisamente en la legitimidad familiar» (págs. 153-154). Pueden verse, en esta línea, los estudios del civilista Manuel de la Cámara, citado en mi libro El ágora y la pirámide. Una visión problemática de la Constitución española, Madrid, Criterio, 2000, págs. 137 y sigs. 
de unas pocas familias que conservan aún relevancia política con otras que la han perdido. Y la democracia, finalmente, supone una sociedad de individuos (supuestamente iguales) en la que la familia se ha eclipsado como agente político (17). No es de extrañar, pues, que la democracia tienda a debilitar la relevancia social de la familia. Lo que sí resulta singular que la propia Iglesia haya cedido últimamente al democratismo imperante a la hora de presentar su enseñanza sobre la familia. En efecto, el Catecismo de San Pío X (núm. 408) afirmaba que la sociedad civil se compone fundamentalmente de familias, mientras que el nuevo (el Catecismo de la Iglesia Católica, de Juan Pablo II), en cambio, dice que es «una cierta suma de personas» (núm. 1880) (18).

También es de indicar que en la insistencia de la precedencia de la familia sobre la comunidad política, propia de la moderna doctrina social de la Iglesia, se advierte (al menos en parte) una finalidad táctica de defensa del orden natural de las agresiones del Estado anticatólico. Una presentación más equilibrada, sin embargo, muestra los tres puntos siguientes sobre la comunidad política y su orden: a) que es una sociedad natural semejante, por ejemplo, a la familia; b) que es contemporánea a las sociedades familiar y civil, es decir, la comunidad política no viene después de las dos primeras, sino con ambas; c) que no «absorbe» en sí a las otras sociedades naturales, sino que es garantía de su exis-

(17) La explicación es, otra vez, de Álvaro D'ORs, Forma de gobierno y legitimidad familiar, Madrid, O crece o muere, 1960.

(18) El mismo profesor d'Ors, que lo señala, reconoce que el giro democrático de la Iglesia, en este punto, se compadece con lo que es más propio de su estructura, que no se compone de familias sino de individuos bautizados. Y añade: «En efecto, aunque la doctrina del magisterio de la Iglesia da gran importancia a la familia como "célula" de la sociedad, el interés efectivo que por ella demuestra se reduce al matrimonio y a la educación cristiana de los hijos. De hecho, no insiste en la discriminación de la legitimidad, reduce la familia a la relación interconyugal y paternofilial, y ha contribuido, a lo largo de la historia, a debilitar la patria potestad sobre los hijos» (Nueva introducción al estudio del derecho, cit., pág. 151). No le falta razón en ninguna de las dos observaciones. Por lo que toca al "giro democrático» de la Iglesia, puede verse el ensayo, bien agudo, de Bernard Dumont, «La monarquía en la doctrina social de la Iglesia», Verbo (Madrid), núm. 535-536 (2015), así como en el volumen de Miguel Ayuso (ed.), Política católica e ideologías, Madrid, Itinerarios, 2015. 
MIGUEL AYUSO

tencia ordenada para conseguir su propio fin (19). Que es sociedad natural implica que, frente al contractualismo, tiene un fin en sí, que debe ser buscado y reconocido: es el bien común. Que es contemporánea con la familia y la sociedad civil implica que no deriva de éstas: que, aunque otra cosa, es condición del ser de ellas, de modo que no resisten si la comunidad política cae (20).

\section{La «evaporación» del matrimonio}

La familia se levanta sobre el matrimonio. De manera que las transformaciones que han producido el «eclipse» de la familia han provocado también la «evaporación» del matrimonio. Así como la debilitación de éste no ha dejado de influir negativamente sobre aquélla. En este sentido puede concluirse que las reformas contemporáneas de la disciplina matrimonial (a comenzar por el divorcio vincular) no sólo han atentado contra el derecho natural sino que incluso han terminado por suponer la desaparición del matrimonio como institución (21).

Se hace preciso, en primer término, considerar el cambio de perspectiva respecto de los fines del matrimonio. Es

(19) Cfr. Danilo Castellano, La naturaleza de la política, Barcelona, Scire, 2006, págs. 52 y sigs., al que seguimos en este desarrollo.

(20) Ibid., pág. 56: «Por tanto, todo proyecto de "defensa" y "recuperación" de la familia y la sociedad que abandone la cuestión del Estado entendido como res publica está destinado al fracaso, puesto que no considera adecuadamente el problema del orden natural. Y, por consiguiente, ya es "desordenada" la acción que subyace en el eslogan más sociedad menos Estado, puesto que abandona a sí mismo el destino de la comunidad política o peor aún, considera que se puede servir de ésta en función de los fines de la sociedad civil, o cree poder "condicionar" a la comunidad política actuando sobre la comunidad civil. La familia, las sociedades civil y política son realidades diversas, autónomas, distintas, pero relacionadas: simul stabunt simul cadent. Pero, sobre todo, son realidades positivas, es decir, indispensables, para que el hombre pueda conseguir su bien».

(21) He apuntado el asunto, sobre el que habremos de volver, en mi «El matrimonio canónico, ¿inconstitucional?», AA.Vv., Hominum causa omne ius constitutum est: escritos sobre el matrimonio en homenaje al prof. Dr. José María Díaz Moreno, S.J., Madrid, Universidad Pontificia Comillas, 2000, págs. 1031 y sigs. 
sabido que el pensamiento de la «modernidad», sobre todo a partir del romanticismo, ha propiciado tensiones desintegradoras, movilizando unas contra otras las dimensiones y facultades de la naturaleza y del hombre, y destruyendo así todo posible dinamismo rectamente ordenado. Que, referidas al matrimonio, la institución humana más originaria, principio insustituible en el orden de la vida individual y social, se han expresado en la objeción que (en nombre del amor) pretende enfrentarse a la jerarquía de fines y bienes afirmada en la filosofía clásica y defendida por el magisterio tradicional católico (22). Así, por ejemplo, a partir de una visión «personalista» (23) que opone antitéticamente la libertad y el amor a la naturaleza y la ley, se ha contemplado la orientación del matrimonio a la procreación como «una esclavización de la libertad humana a la necesidad de la naturaleza»(24).

(22) Cfr. Francisco Canals, «Matrimonio y amor», Verbo (Madrid), núm. 181-182 (1980), pág. 65 y sigs., que seguimos.

(23) El personalismo contemporáneo, en puridad, no se desenvuelve en la línea de la fundamentación metafísica clásica de la persona, sino en la del individualismo o «vitalismo» que ponen en la «libertad negativa» un no-fundamento en el fondo nihilista. Lo que no quita para que algunos autores «clericales» (en el sentido de que se aplican a «bautizar» las tendencias dominantes en cada momento, por alejadas que se hallen de la filosofía clásica y la doctrina católica) hagan contrabando intelectual con los términos y los conceptos. Pueden verse, a este propósito, los análisis de Danilo Castellano, L'ordine político-giuridico «modulare» del personalismo contemporaneo, Nápoles, Edizioni Scientifiche Italiane, 2007.

(24) Las acusaciones de maniqueísmo dirigidas contra el De Bono coniugali, de San Agustín, por ejemplo son profundamente desorientadores. Canals recuerda a este respecto que el sistema maniqueo, que por cierto era radicalmente materialista, no recelaba del sexo como actividad humana, sino precisamente de las consecuencias naturales del mismo: la generación. Y es que, como en otras sectas gnósticas, «en el dualismo maniqueo se invertía de modo perverso la antítesis paulina entre el "espíritu" y la "carne" ": «En San Pablo significaban estos términos la acción del Espíritu de Dios, y el hombre egoísta y cerrado en sí mismo frente al llamamiento de la gracia. En el maniqueísmo, la "carne" no es otra cosa que la naturaleza con sus leyes y fines, mientras que el "espíritu" significa la libertad frente a la naturaleza, o lo que viene a ser lo mismo, la rebeldía de la voluntad humana contra la ley puesta por Dios en la naturaleza misma. La enseñanza católica tuvo siempre que defender las nupcias frente a los ataques, reiterados a lo largo de los siglos, de inspiración maniquea o cáthara $[. .$.$] . Lo maniqueo es, pues, la hostilidad a las inclinaciones de la$ naturaleza, a sus inclinaciones profundas, impresas por la acción creadora 
MIGUEL AYUSO

Muchas mentalidades han llegado así a participar de cierta desazón romántica ante el hecho de que en la definición de matrimonio no apareciera el amor y de que en el derecho canónico no apareciera alusión alguna a lo que parece tan estrechamente ligado a la plenitud del vínculo (matrimonio in fieri) y de la sociedad conyugal (matrimonio in facto ese). Y es que la formulación tradicional hablaba de un fin primario (procreación y educación de la prole), terminología que no sólo no suponía «la unicidad exclusiva de este fin» sino que admitía «la existencia de otros fines secundarios, pero subordinados por lo mismo, esencialmente a aquel fin que es ciertamente el único que puede ser considerado según aquella primacía, y al que se ordenan todos los otros fines del matrimonio: el "muto auxilio" y el "remedio de la concupiscencia”» (25).

En el cuadro de la doctrina tradicional, con todo, no es que estuviera ausente el amor, sino que lo estaba de modo más puro y profundo que en la nueva tocada de personalismo: «El amor de Dios, que ha movido el impulso de comunicación de la voluntad divina, que es causa y motivo final de la creación y de la elevación al orden sobrenatural, se ha expresado en que Dios no sólo comunicó a sus criaturas la participación de sus perfecciones, sino también la capacidad de comunicar y difundir la perfección de que partici-

de Dios mismo, y la invocación como libertad de las inclinaciones desordenadas, desviadas por el egoísmo y la pecaminosidad. Lo maniqueo es el amor libre y el divorcio. La homosexualidad y el aborto» (Francisco CANALS, «Matrimonio y amor», loc. cit., pág. 66).

(25) Francisco Canals, loc. ult. cit., pág. 67. Es de notar que Canals no utilizaba el pretérito sino el presente en su texto, mientras que nosotros, al transcribir lo esencial de su juicio, nos hemos visto obligados a acudir al pasado. Y es que, al escribirlo, en 1980, no se había promulgado el nuevo Código de Derecho Canónico (de 1983), sino que seguía en vigor el llamado pío-benedictino de 1917. Mientras que éste, en su canon 1013, distinguía, como recuerda Canals, entre un fin primario y otro secundario, el canon 1055.1 del nuevo habla de una «alianza matrimonial, por la que el varón y la mujer constituyen entre sí un consorcio de toda la vida, ordenado por su misma índole natural al bien de los cónyuges y a la generación y educación de la prole». Parece claro que el profesor Canals sostenía algo diferente. Aunque, que sepamos, tras la promulgación del nuevo código, no se pronunciara sobre el asunto. 
pan. La fecundidad de la vida es un reflejo de la eterna generación del Hijo de Dios. En el universo creado, ninguna criatura tiene la capacidad de ser, por su misma naturaleza, causa de la existencia de seres personales, creados a imagen y semejanza de Dios, y capaces de felicidad eterna, $a$ no ser el hombre [...]. Sin esta fecundidad propia de la naturaleza humana no es posible la vida histórica de la humanidad en el plano natural, ni tampoco, por lo mismo, la propagación de hecho de la Iglesia como sociedad de los hombres regenerados por la gracia. De aquí, la función especialísima del matrimonio, originador de la familia [...]».

De ahí que «cuando se intenta plantear el problema de los fines del matrimonio desde la perspectiva del enfrentamiento entre el "amor" y la fecundidad, se viene a desconocer la más fundamental perspectiva desde la que puede ser considerado el hombre como ser personal, y su llamamiento a la plenitud propia y a la comunicación de la fe y de la existencia humana» (26).

Habría, a continuación, que abordar el asunto de las propiedades esenciales del matrimonio. La batalla principal

(26) Francisco Canals, ibid., págs. 68-69. Quien explica a continuación los términos de lo que la doctrina tradicional denominaba fin secundario: «La fecundidad de los vivientes, y entre ellos la del hombre, no es operación que pertenezca propiamente a la línea de su voluntad y de su libertad, ni a la de su eficiencia cultural o creatividad artística. La generación es obra de la naturaleza [...]. En la naturaleza humana, la generación propiamente dicha se ejerce por una facultad inherente al propio cuerpo del hombre, como varón y como mujer. Pero Dios ha hecho al hombre dueño de sus actos, providente de sí mismo, en virtud del libre albedrío. $\mathrm{Y}$ ha dispuesto que a la actividad generadora de la naturaleza debiese preceder el acto humano de la unión del varón y la hembra, a través del cual viniesen a darse las condiciones de la fecundidad [...]. Hay que conceder, y afirmar decididamente, que en virtud de esa inclinación natural impresa por Dios al crearles [...], el varón y la hembra hallan en su unión muchos factores de plenitud y maduración personal, además del deleite que se sigue como consecuencia de la operación por la que se unen sexualmente. Aquella plenitud buscada en la sociedad conyugal, es la que en su sentido mutuo y correlativo es correctamente llamada "muto auxilio". En cuanto al deleite como tal, con el cual confunden algunos el concepto de amor conyugal, no puede ser por sí mismo el fin de operación alguna, como vio ya Aristóteles, sino algo que acompaña a una operación que alcanza su propio fin» (págs. 69-70). 
MIGUEL AYUSO

fue la de la introducción, primero, y expansión, después, del divorcio vincular.

La introducción del divorcio vincular en los distintos ordenamientos jurídicos a lo largo del siglo XX asestó al matrimonio un golpe mayor que el que en el precedente supuso el llamado matrimonio civil (27). La doctrina tradicional sobre el matrimonio, codificada en el Código piobenedictino de 1917, siempre sostuvo que el matrimonio era un contrato natural (caracterizado por una esencia y dotada de unas propiedades) elevado a sacramento entre los bautizados. El matrimonio civil, como el mismo registro civil, implicaba, claro está, un factor de secularización en las sociedades cristianas, pues -de un lado-al lado de los registros parroquiales se introducía la llevanza de otros estatales, mientras que -de otro- avanzaba la laicización de los hitos de la vida y la muerte de las personas (28). La existencia de una doble disciplina del matrimonio determinó el nacimiento de lo que se llamó el «sistema matrimonial», donde el Estado (en ocasiones) no sólo se reservó lo relativo al matrimonio civil, sino que se entrometió en el canónico. Sin embargo, el civil (por lo común) siguió revestido de las propiedades esenciales de todo matrimonio: unidad e indisolubilidad.

La oleada divorcista, en cambio, las atacó, y en punto bien sensible para la estabilidad social, profundizando de resultas también por esta vía el proceso de secularización.

(27) Respecto de la gravedad del divorcio, cfr. Álvaro D'Ors, Nueva introducción al estudio del derecho, cit., pág. 152: «En este sentido [el de la lesión de una institución] el divorcio legal resulta más grave que la impunidad legal de cualquier delito, incluso cruento, como puede ser la del feticidio (aborto procurado); del mismo modo que la admisión legal de la poligamia sería más grave, aunque menos cruenta, que la despenalización del uxoricidio; y la abolición de una monarquía, más grave que la despenalización del regicidio; o en otros orden de cosas, la prohibición de la propiedad privada, más grave que la expropiación forzosa».

(28) Los carlistas, por ejemplo, ejemplificando la actitud católica más decidida, hicieron del registro civil un objetivo militar en la tercera guerra, que fue así objeto frecuente de destrucción e incendio. Pueden encontrarse muchos testimonios en las páginas de la monumental Historia del tradicionalismo español (Sevilla, Editorial Católica Española, 1941-1979) de Melchor Ferrer. 
La argumentación que sustentó el divorcio, por ejemplo en Italia en los años setenta y en la España en los ochenta, ayuntaba graves errores de concepción de la política con pseudoargumentos de raíz religiosa (modernista) (29). En efecto, en cuanto toca a los primeros, se hicieron sentir las premisas democráticas (la ley es expresión de la voluntad general), liberales (contraría la libertad individual la vinculación indisoluble aunque el amor haya desparecido) y sociologistas (la evolución social y económica de la familia fuerza, para estar en los hechos, reconocer la posibilidad de disolución del vínculo matrimonial). A las que se añaden, respecto de los segundos, la invocación de la libertad religiosa o, a lo menos, de la tolerancia.

Pero, primeramente, como ya observó Cicerón, «si los derechos se fundaran en la voluntad los pueblos, en las decisiones de los príncipes y las sentencias de los jueces, sería jurídico el robo, jurídico el adulterio, jurídica la suplantación de testamentos, siempre que tuvieran a su favor los votos, o los plácemes, de una masa popular». Y es que, «para distinguir la ley buena de la mala, no tenemos más norma que la naturaleza», con la que se discierne lo justo de lo injusto. «Pensar que esto depende de la opinión de cada uno y no de la naturaleza, es cosa de locos» (30). La perspectiva individualista, seguidamente, es no sólo tendenciosa (pues para resolver los casos sangrantes basta la separación) sino parcial (pues su punto de vista sólo abarca el hipotético bien de los cónyuges y se desentiende de las repercusiones sociales). Y el razonamiento de que las leyes se deben

(29) Véase Juan Vallet de GoYTisolo, «La indisolubilidad del matrimonio según el derecho natural», Verbo (Madrid), núm. 163-164 (1978), págs. 305 y sigs., donde nuestro maestro examina con rigor y buen sentido los argumentos, rectius eslóganes, a favor de la introducción del divorcio.

(30) Cicerón, De legibus, I, XVI, 44. Se debe a Santo Tomás de Aquino la elaboración más precisa de la ley en el pensamiento clásico, como «ordenación de la razón al bien común», que requiere «multa, diligens, subtilior consideratio» de unos pocos sabios y prudentes, que juzguen de lo universal y sobre hechos futuros, adecuándose a las circunstancias de tiempo y lugar, así como a las tradiciones del país y al bien de la comunidad ( $S$. th., I-II, 94 y sigs.). Cfr. Miguel Ayuso, De la ley a la ley. Cinco lecciones sobre legalidad y legitimidad, Madrid, Marcial Pons, 2001. 
MIGUEL AYUSO

adecuar a los hechos olvida totalmente el valor educativo de las leyes y la ayuda que pueden prestar especialmente a los moralmente más débiles (31). Finalmente, desplazándonos al terreno de las motivaciones coloreadas por la religión, debe recordarse que un conocido texto de Santo Tomás con frecuencia colacionado al efecto (32), es de todo punto impertinente. Pues, en el mismo «lo que se propugna es educar paulatinamente y no deseducar moralmente». Se trata de tolerar comportamientos defectuosos, en el sentido de no castigarlos, pero no de degradar las instituciones: «Ello produciría un efecto deseducador y el resultado sería muy contrario al propugnado por Santo Tomás. No penar el adulterio ni el amancebamiento sería tolerar le menage de fait, es decir, el concubinato [...]. En cambio, legalizar el divorcio no sería un mero tolerar un mal social si con ello se degrada la institución del matrimonio y se contribuye a la disolución de las costumbres» (33).

Hubo a la sazón alguna oposición, más en Italia que en España, pues los años transcurridos entre 1970 [fecha de la ley italiana, respecto de la que el intento de un referéndum abrogativo fracasó en 1974 (34)] y 1981 (momento en que

(31) Cfr. Juan Vallet de Goytisolo, Panorama del derecho civil, $2^{a}$ ed., Madrid, Reus, 1973, donde en los primeros capítulos examina críticamente las distintas concepciones del derecho y, entre ellas, la sociologista.

(32) SAnto Tomás DE AQuino, St. th., I-II, 96, a, 2: «El poder o facultad de obrar se debe a una disposición o hábito interior, de aquí que una cosa sea muy posible para el virtuoso y no lo sea tanto para el que carece del hábito de la virtud, así como tampoco puede tanto el niño como el adulto, y por eso no se impone a los niños las mismas leyes que a los adultos. A los niños se les permiten muchas cosas que las leyes de los adultos condenan y sancionan. De la misma manera, a los hombres imperfectos en la virtud hay que permitirles muchas cosas que no podrían tolerarse a las personas virtuosas». Y remacha: «La ley humana pretende inducir a los hombres a la virtud, no repentina, sino gradualmente. Por eso, no impone desde un principio a la multitud de los imperfectos las obligaciones propias de los virtuosos; v. gr., la abstención de todos los males. De otro modo, los imperfectos, no pudiendo cumplir tales preceptos, caerían en vicios aún peores».

(33) Juan VAllet DE GoYTiSOlo, «La indisolubilidad del matrimonio según el derecho natural», loc. cit., pág. 7.

(34) Cfr. Álvaro D’ORS, «La lección del referéndum antidivorcista en Italia», Verbo (Madrid), núm. 267-268 (1988), págs. 1135 y sigs. Elegante 
se introduce en la legislación española) no habían pasado en vano en cuanto a la profundización del deterioro de los restos de Cristiandad. En Italia se opuso inicialmente la Democracia Cristiana, aunque pronto cejó en el empeño. En España fue la propia democracia cristiana (aunque el partido no se denominara así, sino que era la Unión de Centro Democrático, ocupaba exactamente el mismo espacio político, y aun algunos de los intervinientes pertenecían propiamente a la rama democristiana, esto es, la Asociación Católica de Propagandistas) los que, con el acuerdo de la Conferencia Episcopal, en cambio la propiciaron (35). En el decenio de los dos mil, cuando en ambos países -por seguir con el ejemplo- se ha modificado la legislación para introducir el divorcio apodado de «breve» o incluso «exprés», la reacción ha sido bien diferente, demostrando no sólo la dinámica imposible de vencer que introduce el reconocimiento jurídico del divorcio vincular, sino sobre todo la conversión (en realidad perversión) de ambos países al laicismo, secularismo o «radicalismo». El ejemplo resulta particularmente significativo, toda vez que estos países llamados latinos, rectius católicos, iban a la zaga de los protestantes en cuanto a secularización se refiere.

En lo que toca al caso italiano disponemos de un preciso análisis de las posiciones que se encuentran detrás del cambio legislativo, que -con los matices que se quiera- pueden servirnos para su generalización respecto de la «cultura jurídica» contemporánea (36).

En primer lugar, no basta atender a la posición de los legisladores a través del voto. Puesto que entre la minoría que se opuso hubo quien se declaraba contrario a la pro-

crítica de la posición de Gabrio Lombardi, Perché il referendum sul divorzio? (Ares, Milán, 1988), y su inconsistencia democristiana.

(35) El análisis del -a la sazón- obispo de Cuenca, doctor Guerra Campos, lo evidencia sin remilgos y constituye una dura requisitoria contra los políticos de (aparente) adscripción católica y contra buena parte de sus hermanos en el episcopado. Cfr. José Guerra Campos, La ley del divorcio y el Episcopado español (1976-1981), Madrid, ADUE, 1981.

(36) Cfr. Daniele MATTIUSI, «Sull'"evaporazione" del matrimonio», Instaurare (Udine), año XLIII, núm. 2 (2014), págs. 1 y sigs., que seguimos a continuación. 
MIGUEL AYUSO

puesta concreta pero no a la propuesta en sí misma. También hubo quien, oponiéndose a ésta, perseveraba en cambio en la defensa y en el mantenimiento de un ordenamiento jurídico (empezando por el constitucional) que coherentemente conduce al divorcio, incluido el «breve» (37). Incluso ha habido quien ha entendido que la decisión podía venir cubierta por la libertad de conciencia, como si se tratase de una decisión opinable que no afectase a los principios. Finalmente se ha dado el caso de quien, aun contrario, en la vida no sólo ha aceptado sino incluso practicado el divorcio. Así pues, antes que la casi unanimidad política puede advertirse una verdadera unanimidad cultural.

Una segunda observación se refiere a la falta de claras reacciones contrarias. Pese a haberse llegado incluso a la aplicación de los procesos en curso. Esto sirve también para la jerarquía de la Iglesia, que ha callado, pese a la consabida retórica en favor de la familia, no acompañada de una verdadera defensa en la práctica. Hoy la Iglesia no se halla ya en la posición de poder impedir la aprobación de esa u otras análogas leyes. Pues la cultura católica va a remolque de la dominante, que lleva no sólo al divorcio sino aun a la disolución del matrimonio y hasta de la pareja cuando dos personas sienten que han dejado de compartir un proyecto de vida común (38).

En tercer lugar, el himno a la libertad vitalista es prueba de la «deshumanización» del hombre (39). Es signo claro de

(37) Es excelente a este respecto el análisis del maestro de constitucionalistas Pietro Giuseppe GRASSO, Costituzione e secolarizzazione, Padua, CEDAM, 2002. Lo destaca también muy oportunamente Danilo Castellano, «Costituzione e secolarizzazione in Pietro Giuseppe Grasso», Il Politico (Pavía), vol. 73, núm. 1 (2008), págs. 217 y sigs. Con referencia a España puede verse mi El ágora y la pirámide. Una visión problemática de la Constitución española, cit., págs. 105 y sigs.

(38) Cfr. Aa.Vv., Permanecer en la verdad de Cristo. Matrimonio y comunión en la Iglesia Católica, Madrid, Cristiandad, 2013. Libro en el que escriben cinco cardenales (Brandmüller, Burke, Caffarra, Müller y De Paolis) frente las tesis del también cardenal Kasper, antiguas pero de nuevo en el primer plano tras su «relación» al Sínodo extraordinario sobre la familia de octubre de 2014. Cfr. Daniele MATTIUSI, «Sobre el Sínodo extraordinario de la familia», Verbo (Madrid), núm. 533-534 (2015), págs. 183 y sigs.

(39) Sobre el «vitalismo» puede verse Danilo CASTELLANO, «La emer- 
barbarie que se haya llegado a calificar la reforma de «opción de libertad», al anteponer el consentimiento a la obligación, privilegiar la libertad respecto de sus límites y vaciar la norma abstracta para dejar espacio a la práctica concreta. La «liberación» de las obligaciones no es posible siquiera con el consentimiento de las partes. Lo que se entiende mejor cuando, además de pensarse en el matrimonio, se hace también en las obligaciones respecto de los hijos.

Finalmente, la evaporación del matrimonio, como hemos dicho no es nueva. Es el resultado de un proceso puesto por obra hace decenios y que hoy se acerca a su acabamiento, sobre todo por la indiferencia con que ha sido acogida.

Por eso, no se ha tratado sólo del oscurecimiento de la indisolubilidad, sino también progresivamente de la unidad y aun del dato primario de la heterosexualidad. Frente al que debe volverse los ojos, tomando como guía a Santo Tomás, a la visión plena del derecho natural (40). En efecto, fuera de la Revelación, nuestra mente dispone de dos caminos, que deben usarse complementariamente. A través del primero captamos, en realidad de las cosas, los primeros principios especulativos (con el hábito del intellectus principiorum) y prácticos (con el hábito de la sindéresis); mientras que, por medio del segundo, ascendemos de lo singular a lo universal, y de los efectos a las causas. A través, pues, de un doble movimiento, de dimanación o efusión vital (de dentro hacia fuera) y de motivación objetiva (de fuera hacia dentro), se trata de conocer lo justo natural contemplando las

gencia educativa: causas y problemas», Verbo (Madrid), núm. 475-476 (2009), págs. 363 y sigs. El vitalismo, a su vez, está presente en el fenómeno de la «contestación» (que explotó en el 1968) y, en el fondo, del «radicalismo». El propio Castellano ha tratado estos aspectos en «Il ' 68 , ovvero la contestazione», Instaurare (Udine), año XXXVIII, núm. 1 (2009), pág. 6 y sigs., y en La «contestazione», una via cattolica al radicalismo?, Udine, La Nuova Base, 1977. De gran interés resulta el trabajo de Alejandro ORDÓÑEz, Hacia el libre desarrollo de nuestra animalidad, Bucaramanga, Universidad Santo Tomás, 2013.

(40) Puede verse, en general, de Juan Vallet de Goytisolo, «Perfiles jurídicos del derecho natural en Santo Tomás de Aquino», en Estudios jurídicos en homenaje al profesor Federico de Castro, vol. II, Madrid, CSIC, 1976, págs. 705 y sigs., y -aplicado al asunto que nos ocupa- el ya citado «La indisolubilidad del matrimonio según el derecho natural». 
MIGUEL AYUSO

cosas consideradas absolutamente en sí mismas y en relación a sus consecuencias. Así de los primeros principios de la ley natural (41) resultan, del primero, que es lícito el matrimonio entre el varón y la hembra e, inversamente, ilícitas las uniones contra natura; y del segundo que es ilícito no sólo abandonar a la prole sino no educarla adecuadamente (42). Preceptos que se sobreañaden a los primarios, sin que puedan considerarse de menor categoría, sino que aquéllos son tan sólo de más inmediata y elemental captación. La unidad y la indisolubilidad del matrimonio arraigan precisamente ahí. Pues, considerando la cosa en sí misma, observamos que la hembra en la especie humana, a diferencia de otras especies animales, no se basta sola para criar a sus hijos; que la solicitud por los hijos es menor en aquellas especies animales en que el macho puede tener varias hembras; que la certeza de la prole exige que la mujer no tenga varios varones; que los hijos necesitan también instrucción, para la cual en la especie humana requiere el concurso de la razón y la fuerza del padre; que la necesaria certidumbre de la paternidad de la prole se entorpece si el varón puede repudiar a la muer o ésta abandonar a aquél; que la necesidad de instrucción y formación, más allá de la simple crianza, impone que la familia se prolongue hasta que el menor de los hijos haya alcanzado sólidamente la adecuada instrucción y autodominio; que, más aún, el matrimonio se ordena a la educación de la prole no sólo durante algún tiempo, sino mientras viva: pues es de ley natural que los padres atesoren para los hijos y los hijos hereden a los padres. Apuntes que pueden completarse con los que derivan de la contemplación de la cosa en relación a las consecuencias que de ella dimanan, con observaciones psicológicas (sobre la intensidad de la amistad entre hombre y mujer cuando se extiende

(41) Los primeros principios se deducen de las primeras inclinaciones: una, común a todos los seres vivos, como el instinto de conservación; otra, común a todos los animales, como la comunicación sexual y la educación de la prole; otra última, exclusiva de nuestra naturaleza racional, como conocer las verdades (divinas y naturales) y vivir en sociedad ( $S$. th., I-II, 94, 2).

(42) S. th., II-II, 57, 3, respondeo. 
no sólo a la cópula carnal sino a la total comunidad de vida) y sociales (la unión indisoluble entre marido y mujer afecta verdaderamente a las buenas costumbres) (43).

\section{Conclusión}

El camino que nos muestra el Aquinate, y que reclama la atención a la experiencia y a las conclusiones que a partir de éstas nos enseñan las ciencias, viene así a coincidir con la definición de jurisprudencia (prudentia iuris) acuñada por Ulpiano: la ciencia de lo justo y de lo injusto que se vale para tal tarea de los datos que le ofrecen todos los conocimientos divinos y humanos (44). De donde concluye Vallet: «Las sencillas pero claras y certeras observaciones de Santo Tomás de Aquino acerca de la indisolubilidad del matrimonio, a la luz del método del Derecho natural clásico, se ven tanto más confirmadas cuanto más se profundiza, examinando la cosa -el divorcio- en relación a las consecuencias qué produce. Nos lo muestran las actuales experiencias que el auge divorcista va poniendo con más evidencia al descubierto, los datos que las estadísticas más recientes recogen, los hechos que la sociología va destacando y los efectos que la psicología infantil y la psiquiatría registran en los hijos de divorciados, que así explican lo que ya iban haciendo vislumbrar las estadísticas de la criminalidad. Estas observaciones muestran y significan bastante más que la afirmación de que el

(43) S. c. g., III, 122 y sigs.; $S$. th., supl., 67, 1. De ahí que un positivista como Augusto Comte, basándose en razones psicológicas, abogara por el matrimonio indisoluble: Auguste ComTe, Système de politique positive ou traité de sociologie, París, Giard y Brière, 1912, II, 3, pág. 182. Y es que «no puede haber equilibrio o armonía psicológicos sin una mínima vivencia de la seguridad, la fidelidad y la dignidad: en suma, de la estabilidad de un conjunto básico de relaciones, afectos, confianzas y protecciones». Cfr. Francisco PuY, «La familia como comunidad de equilibrio humano y social», Persona y Derecho (Pamplona), núm. 1 (1974), pág. 15. Por eso, la familia, célula básica insustituible para el bien común por su valor educativo, necesita basarse en el matrimonio monogámico e indisoluble. Cfr. Marcel DE CORTE, «La educación política», Verbo (Madrid), núm. 59 (1967), págs. 633 y sigs.

(44) Digesto, 1, 1, 10, 2. 
MIGUEL AYUSO

matrimonio debe ser indisoluble. Implican que el matrimonio, verdaderamente tal, es indisoluble; que la indisolubilidad, como la unidad, constituye una cualidad intrínseca y esencial al concepto natural de matrimonio, aunque esta palabra no siempre se aplique con esa propiedad terminológica» (45).

(45) Juan VAllet de GoYTisolo, loc. ult. cit., pág. 333. 